\title{
Potential ecological risk assessment and prediction of soil heavy-metal pollution around coal gangue dump
}

\author{
X. Jiang ${ }^{1}$, W. X. Lu ${ }^{1, *}$, H. Q. Zhao ${ }^{2}$, Q. C. Yang ${ }^{1}$, and Z. P. Yang ${ }^{3}$ \\ ${ }^{1}$ Key Laboratory of Groundwater Resources and Environment, Ministry of Education, Jilin University, Changchun, 130021, \\ China; College of Environment and Resources, Jilin University, Changchun, 130021, China \\ ${ }^{2}$ Shenyang Institute of Geology and Mineral Resources, Shenyang, 110032, China \\ ${ }^{3}$ Key Laboratory of New Technology for Construction of Cities in Mountain Area (Chongqing University), \\ Ministry of Education, Chongqing, 400045, China \\ Correspondence to: W. X. Lu (luwenxi@jlu.edu.cn)
}

Received: 14 June 2013 - Published in Nat. Hazards Earth Syst. Sci. Discuss.: 7 March 2014

Revised: 11 February 2014 - Accepted: 15 May 2014 - Published: 27 June 2014

\begin{abstract}
The aim of the present study is to evaluate the potential ecological risk and trend of soil heavymetal pollution around a coal gangue dump in Jilin Province (Northeast China). The concentrations of $\mathrm{Cd}, \mathrm{Pb}$, $\mathrm{Cu}, \mathrm{Cr}$ and $\mathrm{Zn}$ were monitored by inductively coupled plasma mass spectrometry (ICP-MS). The potential ecological risk index method developed by Hakanson (1980) was employed to assess the potential risk of heavy-metal pollution. The potential ecological risk in the order of $E_{\mathrm{R}}(\mathrm{Cd})>E_{\mathrm{R}}(\mathrm{Pb})>E_{\mathrm{R}}(\mathrm{Cu})>E_{\mathrm{R}}(\mathrm{Cr})>E_{\mathrm{R}}(\mathrm{Zn})$ have been obtained, which showed that $\mathrm{Cd}$ was the most important factor leading to risk. Based on the Cd pollution history, the cumulative acceleration and cumulative rate of $\mathrm{Cd}$ were estimated, then the fixed number of years exceeding the standard prediction model was established, which was used to predict the pollution trend of $\mathrm{Cd}$ under the accelerated accumulation mode and the uniform mode. Pearson correlation analysis and correspondence analysis are employed to identify the sources of heavy metals and the relationship between sampling points and variables. These findings provided some useful insights for making appropriate management strategies to prevent or decrease heavy-metal pollution around a coal gangue dump in the Yangcaogou coal mine and other similar areas elsewhere.
\end{abstract}

\section{Introduction}

Coal is the main fossil fuel in China and it provides more than 70 percent of total energy. The considerable growth of the mining industry in China over the last decades has resulted in a large number of mining waste accumulated in wastelands. This waste in addition to its land use impact cause water and soil pollution as well as soil erosion and other environmental problems (Querol et al., 2008). Mining industry generated $265 \mathrm{Mt}$ tailings, $130 \mathrm{Mt}$ gangue, and $107 \mathrm{Mt}$ smelting slag in 2002 (Querol et al., 2008). Among which, the one of most concern is coal gangue, which as the direct outputs of coal mining has substantially generated and accumulated around coal mine area. Currently, the cumulative amount of coal gangue in China was estimated to be more than 5.0 billion tons given the large coal production. Despite its economic and social benefit, the generation and accumulation of coal gangue has brought a variety of environmental and social problems. Among which heavy-metal pollution is the most concern (Gong et al., 2008). Exposed to weathering, leaching and decomposing, water containing heavy-metal elements will be emitted into the soil. Heavymetal pollution in soil around coal gangue dumps is a threat to human health because it can be easily transferred into the human body through ingestion via the hand-mouth pathway, inhalation and dermal contact. Moreover, the long-term input of heavy-metal elements could result in decreased buffering capacity of soil, threatening the ecological environment. 
In recent years, heavy-metal pollution caused by the considerable growth of the mining industry and the effects of human activity has called for extensive concern worldwide. Many researchers have performed related researches on mineral composition in coal gangue (Zhou et al., 2012; Fernandes, 1997), chemical speciation of heavy metals in coal gangue (Dang et al., 2002), pollution characteristics of heavy metal in soil (Dragović et al., 2008; Luan et al., 2008), and potential ecological risk assessment of soil heavy-metals contamination around coal gangue piles (Abdu et al., 2011; Krishna and Govil, 2008; Zhao et al., 2012). However, the pollution trend of heavy metal in soil around coal gangue dumps has received less formal attention than it should have.

Yangcaogou coal mine is a large state-owned coal mine in Changchun, Northeast China. Since the coal mine was put into production, the average annual emission of coal gangue is about $20300 \mathrm{~m}^{3}$, and the coal gangue is mainly accumulated within the industrial square. Without taking any protection and treatment measures, soil around the coal gangue dump has been polluted to a certain degree. It is particularly significant to evaluate the potential ecological risk and predict the pollution trend of heavy metal in soil around the coal gangue dump in order to carrying out a targeted control or prevention measures. However, few studies could be found in literature about this area. This work presents a study on the heavy-metal pollution analysis, potential ecological risk assessment and prediction of soil heavy-metal pollution around a coal gangue dump with the Yangcaogou coal mine as the study area. The present work was performed via investigation, field sampling, laboratory experiment and mathematical analysis.

In this paper, pollution index (PI) and Nemerow integrated pollution index (NIPI) methods were attributed to evaluate the degree of heavy-metal contamination. Pearson correlation analysis and correspondence analysis were employed to address the source of heavy metals. Single and integrated ecological risk index were calculated to reveal the potential risk of heavy metals. In addition, the fixed number of years exceeding the standard prediction model was established to predict the pollution trend of $\mathrm{Cd}$ (the key influence factor to cause the risk) in soil around coal gangue dump in the future.

The objectives of the present study were (1) to determine total concentrations of heavy metals $(\mathrm{Cd}, \mathrm{Pb}, \mathrm{Cu}, \mathrm{Cr}$ and $\mathrm{Zn})$ in soil around a coal gangue dump, (2) to evaluate the extent of heavy-metals pollution in soil based on PI and NIPI, (3) to identify the source of heavy metals by Pearson correlation analysis and corresponding analysis, (4) to evaluate the potential ecological risk and predict the pollution trend of heavy metal $\mathrm{Cd}$ in soil around the coal gangue dump. The contribution of the present study is to provide useful insights for seeking appropriate management strategies to prevent or decrease soil heavy-metal contamination around a coal gangue dump in the Yangcaogou coal mine and other similar areas.

\section{Materials and methods}

\subsection{Study area}

Yangcaogou coal mine is located in the eastern part of Changchun city, Jilin Province, China. It lies between latitudes $43^{\circ} 35^{\prime} 59^{\prime \prime} \mathrm{N}$ and $43^{\circ} 56^{\prime} 44^{\prime \prime} \mathrm{N}$, and longitudes $125^{\circ} 34^{\prime} 58^{\prime \prime} \mathrm{E}$ and $125^{\circ} 38^{\prime} 20^{\prime \prime} \mathrm{E}$, with an area of over $16 \mathrm{~km}^{2}$

(Fig. 1). It is a major coal production base in Jilin Province with over 20 years of mining history. The climate in the study area is characterized with continental monsoon climate. The annual average temperature of the region is $4.6^{\circ} \mathrm{C}$ and the average annual rainfall is $569.6 \mathrm{~mm}$. The geology of this region consists of quaternary deposits and the natural soil types, black soil, dark brown soil and meadow soil are the main geological formations according to the classification and codes for Chinese soil. The land contains cultivated land, planting corn and soybean. The prevailing wind direction is from the southwest throughout the year. The mean annual wind speed is $5-6 \mathrm{~m} \mathrm{~s}^{-1}$, and the maximum wind speed is $30 \mathrm{~m} \mathrm{~s}^{-1}$.

\subsection{Sampling design and analysis procedure}

\subsubsection{Sampling}

A 15-year-old and highly weathered coal gangue dump in Yangcaogou coal mine was selected for this study. This coal gangue dump is a cone with a diameter of $40 \mathrm{~m}$ and a height of $15 \mathrm{~m}$.

Generally, the heavy metals in coal gangue are emitted into the soil environment two ways: (1) coal gangue dust by wind erosion suspended in the atmosphere land in the soil around the coal gangue dump, and (2) the contaminants formed by the atmospheric precipitation eluviations move into the soil with runoff. The dissolution transport by the atmospheric precipitation eluviations, weathering, wind-driven solid particle, and soil retention are the expected contaminant transport processes. The wind-driven contamination is one of the processes, but the active weathering related to chemical reaction processes is more relevant in terms of contamination potential.

The prevailing wind direction is from the southwest throughout the year, and the slope is in the northeastern direction in the study area. Considering the wind direction and the local slope direction, along the center of the coal gangue dump, three sampling lines (L1, L2 and L3) were designed, with each sample having a mass of approximately $1.0 \mathrm{~kg}$. The different depths $(0.15,0.4,0.8,1.2,1.6,2.0,2.5$ and $3.0 \mathrm{~m})$ of soil samples were collected through drilling, and the samples had much moisture. The coordinates of the sampling locations were recorded with a GPS receiver, and sample characteristics were described during the fieldwork. The location distribution of drilling holes (sampling points) is shown in Fig. 1. 

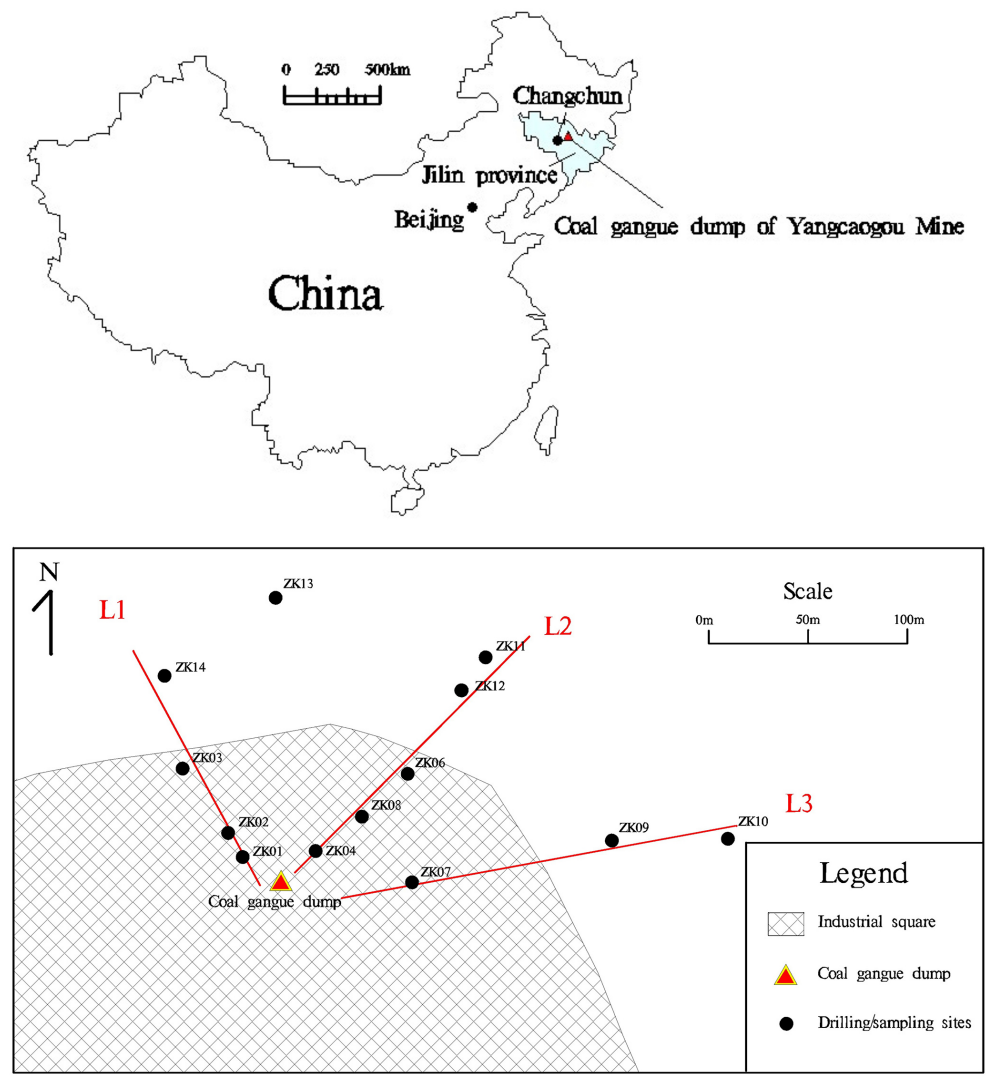

Figure 1. Location of Yangcaogou Mine and soil sampling points around the coal gangue dump (the red lines represent sampling lines).

Coal gangue is a heterogeneous material, and the total concentrations of heavy metals $(\mathrm{Cd}, \mathrm{Pb}, \mathrm{Cu}, \mathrm{Cr}$ and $\mathrm{Zn})$ in the surface (i.e., weathered) of the coal gangue dump were higher than deeper portions. In order to make the gangue samples to be representative, four samples from different depths (depth $=2,3,4$ and $5 \mathrm{~m}$ ) of the coal gangue dump were collected.

The materials of coal gangue samples were mixed rockcoal of big, medium and small grain size. The main mineral composition of coal gangue was kaolinite, and also contains a small amount of quartz. The soil textures are mainly silty clay and silt loam. The materials of some soil samples were mixed with some coal gangue. The soil and coal gangue samples were dried and ground in laboratory, and then were sieved using a $1 \mathrm{~mm}$ sieve for $\mathrm{pH}$ measurement experiment and $0.075 \mathrm{~mm}$ sieve for heavy-metals measurement experiment.

Since heavy-metal contamination risk to human health via ingestion and dermal contact is the most significant in the topsoil, the main research object in this paper was topsoil. However, most of the soil surface has been covered with coal gangue, and the thickness of the cover was about $0.2 \mathrm{~m}$. Consequently, soil from a depth of $0.4 \mathrm{~m}$ was chosen as topsoil for heavy-metal pollution analysis based on field survey (see the Supplement).

\subsubsection{Detection and analysis methods}

All analyses were completed in the Experimental Center Testing Science of Jilin University, which is a research institute that passed the national metrology authentication of China. The prepared soil and coal gangue samples were passed through a $0.075 \mathrm{~mm}$ sieve for heavy-metal measurement experiment. For each sample, a $0.1 \mathrm{~g}$ sample was digested using $3 \mathrm{~mL} \mathrm{HNO}_{3}$ (68\%, GR) $1 \mathrm{~mL} \mathrm{HF} \mathrm{(40 \% ,} \mathrm{GR),}$ and $1 \mathrm{~mL} \mathrm{H} \mathrm{H}_{2} \mathrm{O}_{2}(30 \%, \mathrm{GR})$, for measuring the heavy-metal concentrations. The concentrations of $\mathrm{Cd}, \mathrm{Pb}, \mathrm{Cu}, \mathrm{Cr}$ and $\mathrm{Zn}$ were determined by inductively coupled plasma mass spectrometry (ICP-MS, Aglient 7500a, USA).

For each sample, $10 \mathrm{~g}$ of $1 \mathrm{~mm}$ sieved sample was weighted using a electronic balance for measuring the $\mathrm{pH}$ of the soil or coal gangue. Values of $\mathrm{pH}$ were measured in $25 \mathrm{~mL}$ of deionized water (DI water) with a soil / solution ratio of $1: 2.5(\mathrm{~m} / \mathrm{v})$, using the glass electrode method (GL, pHS-3C, REX, Shanghai, China) according to the agricultural sector standard (NY/T 1377-2007) of the People's Republic China (Eidukeviciene et al., 2010; Ščančar et al., 2000; Kim et al., 2012; Yang et al., 2008).

Descriptive statistics, including the range, mean, standard deviation (SD) and coefficient of variation (CV) were performed. The SD and CV were incorporated to represent the 
degree of dispersion distribution of different heavy metals and to indirectly indicate the activity of the selected elements in the examined environment (Han et al., 2006).

\subsection{Methods of heavy-metal pollution assessment}

To assess the degree of heavy-metal contamination, pollution index (PI) for each metal and Nemerow integrated pollution index (NIPI) (Yang et al., 2011) for the five heavy metals were attributed to each sample. The PI was defined as follows:

$\mathrm{PI}=C_{i} / S_{i}$,

where $C_{i}$ is the measured concentration of each metal $(\mathrm{Cd}$, $\mathrm{Pb}, \mathrm{Cu}, \mathrm{Cr}, \mathrm{Zn})$ in this study, $S_{i}$ is the background value in this paper, the PI of each metal is classified as non-pollution (PI $<1$ ), low level of pollution ( $1 \mathrm{PI}<2$ ), moderate level of pollution $(2 \leq \mathrm{PI}<3)$, strong level of pollution $(3 \mathrm{PI}<5)$ and very strong level of pollution (PI 5) (Yang et al., 2011). The NIPI of the five metals for each sample is defined as follows:

$\mathrm{NIPI}=\sqrt{\frac{\mathrm{PI}_{i \mathrm{ave}}^{2}+\mathrm{PI}_{i \max }^{2}}{2}}$,

where $\mathrm{PI}_{i \max }^{2}$ is the maximum PI value of each heavy metal and $\mathrm{PI}_{i \text { ave }}^{2}$ is the mean PI value of each heavy metal. The NIPI is classified as non-pollution (NIPI $\leq 0.7$ ), warning line of pollution $(0.7<\mathrm{NIPI} \leq 1)$, low level of pollution $(1<\mathrm{NIPI} \leq 2)$, moderate level of pollution $(2<\mathrm{NIPI} \leq 3)$ and high level of pollution (NIPI $>3$ ) (Yang et al., 2010). The calculated results are summarized in the Results section at the end of this paper.

\subsection{Methods of potential ecological risk assessment}

This research employed the Potential Ecological Risk Index (PERI) proposed by Hakanson (1980) to evaluate the potential ecological risk of heavy metals. This method comprehensively considers the synergy, toxic level, concentration of the heavy metals and ecological sensitivity of heavy metals (Nabholz, 1991; Singh et al., 2010; Douay et al., 2013). PERI is formed by three basic modules: degree of contamination $\left(C_{\mathrm{D}}\right)$, toxic-response factor $\left(T_{\mathrm{R}}\right)$ and potential ecological risk factor $\left(E_{\mathrm{R}}\right)$. According to this method, the potential ecological risk index of a single element $\left(E_{\mathrm{R}}^{i}\right)$ and comprehensive potential ecological risk index (RI) can be calculated via the following equations:

$$
\begin{aligned}
C_{\mathrm{f}}^{i} & =C_{\mathrm{D}}^{i} / C_{\mathrm{R}}^{i} \\
E_{\mathrm{R}}^{i} & =T_{\mathrm{R}}^{i} \times C_{\mathrm{f}}^{i} \\
\mathrm{RI} & =\sum_{i=1}^{m} E_{\mathrm{R}}^{i},
\end{aligned}
$$

Table 1. The adjusted grading standard of potential ecological risk of heavy metals in soil.

\begin{tabular}{lllcl}
\hline$E_{\mathrm{R}}^{i}$ & $\begin{array}{l}\text { Pollution } \\
\text { degree }\end{array}$ & $\mathrm{RI}$ & $\begin{array}{l}\text { Risk } \\
\text { level }\end{array}$ & $\begin{array}{l}\text { Risk } \\
\text { degree }\end{array}$ \\
\hline$E_{\mathrm{R}}^{i}<30$ & Slight & $\mathrm{RI}<40$ & $\mathrm{~A}$ & Slight \\
$30 \leq E_{\mathrm{R}}^{i}<60$ & Medium & $40 \leq \mathrm{RI}<80$ & $\mathrm{~B}$ & Medium \\
$60 \leq E_{\mathrm{R}}^{i}<120$ & Strong & $80 \leq \mathrm{RI}<160$ & $\mathrm{C}$ & Strong \\
$120 \leq E_{\mathrm{R}}^{i}<240$ & Very strong & $160 \leq \mathrm{RI}<320$ & $\mathrm{D}$ & Very strong \\
$E_{\mathrm{R}}^{i} \geq 240$ & Extremely & $\mathrm{RI} \geq 320$ & - & \\
& strong & & & \\
\hline
\end{tabular}

where $C_{\mathrm{D}}^{i}$ is the measured concentration of heavy metal in each sampling point; $C_{\mathrm{R}}^{i}$ is reference value, here the background value of each heavy metal in soil is used; $C_{\mathrm{f}}^{i}=C_{\mathrm{D}}^{i} / C_{\mathrm{R}}^{i}$ is the pollution of a single element factor; $E_{\mathrm{R}}^{i}$ is the potential ecological risk index of a single element; $\mathrm{RI}$ is a comprehensive potential ecological risk index; and $T_{\mathrm{R}}^{i}$ is the biological toxic factor of a single element, which is determined for $\mathrm{Zn}=1, \mathrm{Cr}=2, \mathrm{Cu}=\mathrm{Pb}=5$ and $\mathrm{Cd}=30$ (Hakanson, 1980).

Classic PERI method considers eight pollutants, including PCBs, $\mathrm{Hg}, \mathrm{Cd}, \mathrm{As}, \mathrm{Pb}, \mathrm{Cu}, \mathrm{Cr}$ and $\mathrm{Zn}$. However, we did not consider PCBs, $\mathrm{Hg}$ and As in this paper. Due to the difference in pollutant types and quantity, the present study adjusted the grading standard of heavy metals' ecological risk indices based on the types and quantity of pollutants ( $\mathrm{Li}$ et al., 2012). We made the maximum value of $T_{\mathrm{R}}^{i}$ as the lowest level limit of $E_{\mathrm{R}}^{i}$, and the remaining level limits followed by doubles. Making the rounding digit of $\sum^{m} T_{\mathrm{R}}^{i}$ as the lowest level limit of RI, and the remaining level limits followed by doubles (Li et al., 2012). The adjusted grading standards of potential risk of heavy metals in soil were summarized in Table 1.

\subsection{Prediction methods of heavy-metals pollution}

It is a well-recognized opinion that when heavy metal is emitted into soil, it will experience a series of complicated physical, chemical and biological reactions. In the view of the dynamic equilibrium, the concentrations of heavy metals in soil can be predicted when the flux of input and output heavy metals within a certain period of time is clearly known. However, the flux of input and output heavy metals in the future is usually unknown, so it is very difficult to quantitatively forecast the pollution trend of heavy metals using the dynamic equilibrium model. In view of this, Fan et al. (2005) and Yan et al. (2007) developed early warning methods to forecast the pollution trend of heavy metal in the future through reasonable default of future scenarios, and it has achieved good results in practical application. Due to a lack of series historical data of heavy-metal concentrations in soil in this area, a regression prediction model to forecast the future situation can not be established. Therefore, the early warning method mentioned above was employed to predict the pollution trend 
of the heavy metal $\mathrm{Cd}$ in the soil around coal gangue dump in this paper.

Some soil scientists think that the higher industrialization degree, the greater "contribution" to the soil pollution (Yan et al., 2007; Fan et al., 2005) and the pollutants accumulation in the soil is not uniform but with an accelerated speed. They are suggesting that increased industrial development will not change the impact on soil quality if strong environmental protection methods are implemented and hence the accumulation of pollutants in soil will remain uniform as opposed to develop with an increasing speed (Yang et al., 2010).

The history of soil pollution caused by coal gangue in the study area can be traced back to 1989, when it was put into operation. Since 2012, thorough investigation and research on heavy-metal pollution in soil were conducted. Based on the above analysis, the present study intended to use 2012 as a benchmark year, the 23 years (from the year of 1989 to 2012) served as a accelerating stage, using the measured values of heavy metals in 2012 to calculate cumulative acceleration rate and cumulative rate (for 2012). The present study set 2013 as the starting forecast year.

The formula of heavy-metal element accumulation per unit in soil $(Q)$ can be written as

$Q=a-b$

$A=2 Q / T^{2}$

$V_{0}=A \times T$,

where $a$ is heavy-metal concentration in each soil sample (measured concentration of heavy metal in soil in 2012), $\mathrm{mg} \mathrm{kg}^{-1} ; b$ is the background value of heavy metal in soil, $\mathrm{mg} \mathrm{kg}^{-1} ; A$ is cumulative acceleration rate; $V_{0}$ is cumulative rate (the year of 2012); and $T=23$ (the total heavy-metal accumulation years since the coal mine was put into production).

\subsubsection{Accelerated accumulation mode}

If social environment protection consciousness is poor in the future, with a lack of environmental protection measures, the accumulation of heavy metals in the soil will be speed up. The computation formula of the fixed number of years exceeding standard is as follows:

$t=\sqrt{V_{0}^{2}-2 A(c-a)} / A$.

\subsubsection{Uniform mode}

If social environment protection consciousness is strengthened in the future, increased industrial development will not change the impact on soil quality according to the environmental protection strategy. In other words, the pollution velocity of soil heavy metals will stay constant. The computation formula is as follows:

$t=Q / V_{0}$, where $c$ is the value of soil environment quality standard (national primary and secondary standard GB 15618-1995), $\mathrm{mg} \mathrm{kg}-1 ; a$ is the concentration of heavy-metal elements in soil, $\mathrm{mg} \mathrm{kg}^{-1}, t$ is fixed number of years exceeding standard, the unit is year; and the notations of $A, V_{0}$ and $Q$ are the same as in Eqs. (6)-(8).

\section{Results and discussion}

\subsection{Characteristics of heavy-metal concentrations in coal gangue and the background values}

There were four samples from different depths (depth $=2,3$, 4 and $5 \mathrm{~m}$ ) of the coal gangue dump were collected. Eight reference "background" samples (depth $=0.15,0.4,0.8,1.2$, $1.6,2.0,2.5$ and $3.0 \mathrm{~m}$ ) were taken at the place where the distance from the coal gangue dump is more than $600 \mathrm{~m}$ and this place is not affected by coal gangue. However, the main research object in this paper is topsoil (depth $=0.4 \mathrm{~m}$ ), so we chose the heavy-metal concentration in the "background" sample at a depth of $0.4 \mathrm{~m}$ as the background value. The analysis results of heavy metals in coal gangue and the background values of soil in Yangcaogou coal mine are listed in Table 2.

The average of $\mathrm{pH}$ values in coal gangue samples was 8.63 , showing a strong alkaline property. Compared with the Environmental Quality Standard for Soils in China published by National Environmental Protection Agency of China (NEPA, 1995), the mean concentrations of $\mathrm{Cu}, \mathrm{Cd}$ and $\mathrm{Pb}$ in coal gangue were lower than the national primary standard of agricultural soil, and the mean concentrations of $\mathrm{Cr}$ and $\mathrm{Zn}$ were lower than the national secondary standard. However, the mean concentrations of the five types of heavy metals in coal gangue were all higher than background values of soil in the study area, with excessive multiples with order of $\mathrm{Cd}>\mathrm{Zn}>\mathrm{Cr}>\mathrm{Cu}>\mathrm{Pb}$.

\subsection{Characteristic analysis of $\mathrm{pH}$ value and concentration of heavy metal in soil}

The $\mathrm{pH}$ value of soil was usually divided into five grade, that is, slightly acidic ( $\mathrm{pH}<5.0)$, mildly acidic $(5.0 \sim 6.5)$, neutral $(6.5 \sim 7.5)$, mildly alkaline $(7.5 \sim 8.5)$ and the strongly alkaline ( $\mathrm{pH}>8.5$ ). The $\mathrm{pH}$ values of soil around the coal gangue dump ranged from 5.48 to 7.91 , which implied a gradual change from mildly acidic to mildly alkaline. The change trend of $\mathrm{pH}$ value in each sampling line is similar, inversely proportional to the distance from the coal gangue dump.

Compared with Environmental Quality Standard for Soils in China (GB 15618-1995), the mean concentrations of Cd, $\mathrm{Zn}, \mathrm{Pb}, \mathrm{Cu}$ and $\mathrm{Cr}$ in topsoil were lower than the national primary standard of agricultural soil. However, the mean concentrations of $\mathrm{Zn}, \mathrm{Cd}$ and $\mathrm{Pb}$ were higher than background values, and the mean concentrations of $\mathrm{Cu}$ and $\mathrm{Cr}$ in most 
Table 2. The statistical analysis of heavy metals in topsoil samples, the background values and coal gangue samples.

\begin{tabular}{|c|c|c|c|c|c|c|c|c|c|c|c|}
\hline \multicolumn{7}{|c|}{ Topsoil samples } & \multirow{2}{*}{$\begin{array}{l}\text { Background } \\
\text { values } \\
\left(\mathrm{mg} \mathrm{kg}^{-1}\right)\end{array}$} & \multicolumn{4}{|c|}{ Coal gangue } \\
\hline Element & $\begin{array}{l}\text { Sampling } \\
\text { line }\end{array}$ & $\begin{array}{l}\text { Minimum } \\
\left(\mathrm{mg} \mathrm{kg}^{-1}\right)\end{array}$ & $\begin{array}{c}\text { Maximum } \\
\left(\mathrm{mg} \mathrm{kg}^{-1}\right)\end{array}$ & $\begin{array}{r}\text { Mean } \\
\left(\mathrm{mg} \mathrm{kg}^{-1}\right)\end{array}$ & SD & $\mathrm{CV}$ & & $\begin{array}{l}\text { Mean } \\
\left(\mathrm{mg} \mathrm{kg}^{-1}\right)\end{array}$ & $\begin{array}{l}\text { Median } \\
\left(\mathrm{mg} \mathrm{kg}^{-1}\right)\end{array}$ & SD & $\mathrm{CV}$ \\
\hline \multirow{3}{*}{$\mathrm{Cr}$} & L1 & 59.75 & 77.43 & 66.48 & 8.2 & 0.12 & \multirow{3}{*}{71.22} & \multirow{3}{*}{92.29} & \multirow{3}{*}{88.71} & \multirow{3}{*}{27.21} & \multirow{3}{*}{0.29} \\
\hline & L2 & 57.11 & 80.54 & 69.69 & 9.01 & 0.13 & & & & & \\
\hline & L3 & 65.02 & 80.54 & 72.88 & 7.76 & 0.11 & & & & & \\
\hline \multirow{3}{*}{$\mathrm{Cu}$} & L1 & 18.82 & 21.46 & 20.52 & 1.25 & 0.06 & \multirow{3}{*}{20.39} & \multirow{3}{*}{24.81} & \multirow{3}{*}{25.55} & \multirow{3}{*}{3.24} & \multirow{3}{*}{0.13} \\
\hline & L2 & 20.63 & 22.58 & 21.57 & 0.83 & 0.04 & & & & & \\
\hline & L3 & 21.83 & 23.02 & 22.6 & 0.67 & 0.03 & & & & & \\
\hline \multirow{3}{*}{$\mathrm{Zn}$} & L1 & 59.36 & 68.81 & 64.45 & 3.94 & 0.06 & \multirow{3}{*}{51.07} & \multirow{3}{*}{107.89} & \multirow{3}{*}{111.6} & \multirow{3}{*}{20.34} & \multirow{3}{*}{0.19} \\
\hline & $\mathrm{L} 2$ & 61.27 & 68.73 & 64.51 & 2.97 & 0.05 & & & & & \\
\hline & L3 & 61.11 & 72.27 & 67.55 & 5.77 & 0.09 & & & & & \\
\hline \multirow{3}{*}{$\mathrm{Cd}$} & L1 & 0.13 & 0.18 & 0.16 & 0.02 & 0.14 & \multirow{3}{*}{0.06} & \multirow{3}{*}{0.18} & \multirow{3}{*}{0.18} & \multirow{3}{*}{0.04} & \multirow{3}{*}{0.21} \\
\hline & L2 & 0.12 & 0.17 & 0.15 & 0.02 & 0.11 & & & & & \\
\hline & L3 & 0.13 & 0.17 & 0.16 & 0.02 & 0.15 & & & & & \\
\hline \multirow{3}{*}{$\mathrm{Pb}$} & L1 & 19.54 & 20.16 & 19.92 & 0.29 & 0.01 & \multirow{3}{*}{19.35} & \multirow{3}{*}{21.3} & \multirow{3}{*}{21.67} & \multirow{3}{*}{3.25} & \multirow{3}{*}{0.15} \\
\hline & L2 & 19.42 & 23.7 & 20.85 & 1.8 & 0.09 & & & & & \\
\hline & L3 & 19.29 & 23.64 & 22.15 & 2.48 & 0.11 & & & & & \\
\hline
\end{tabular}

soil samples were higher than background values, indicating that coal gangue dump had polluted the soil around coal gangue dump. The concentrations of heavy metals in the topsoil around coal gangue dump and their descriptive statistical results are listed in Table 2 . The concentration distribution contour maps of $\mathrm{pH}, \mathrm{Cd}, \mathrm{Pb}, \mathrm{Cu}, \mathrm{Cr}$ and $\mathrm{Zn}$ in the topsoil around the coal gangue dump are showed in Fig. 2.

\subsection{Heavy-metal pollution assessment}

Based on the monitoring data of soil quality in the study area, a quantitative analysis of heavy-metal pollution in soil around the coal gangue dump was conducted using the method of PI and NIPI (Yang et al., 2010). The PI values varied greatly among heavy metals. The PI values of $\mathrm{Cr}$ and $\mathrm{Cu}$ in soil around coal gangue dump ranged from 0.80 to 1.13 and from 0.92 to 1.13 , respectively, indicating that the soil was uncontaminated to slightly contaminate by $\mathrm{Cr}$ and $\mathrm{Cu}$. The $\mathrm{PI}$ values of $\mathrm{Zn}$ and $\mathrm{Pb}$ in soil around coal gangue dump ranged from 1.16 to 1.42 and from 1.00 to 1.22 , respectively, indicating that the soil was slightly contaminated by $\mathrm{Zn}$ and $\mathrm{Pb}$. The $\mathrm{PI}$ values of $\mathrm{Cd}$ in soil around coal gangue dump ranged from 2.05 to 2.84 , indicating that the soil was moderately contaminated by $\mathrm{Cd}$. The analysis results showed that the average of PI descended in the order of $\mathrm{Cd}(2.43)>\mathrm{Zn}(1.27)>\mathrm{Pb}(1.08)>\mathrm{Cu}(1.05)>\mathrm{Cr}(0.98)$.

The NIPI values in soil around the coal gangue dump ranged from 1.71 to 2.24. Eight units of soil samples were lightly polluted (NIPI ranged from 1.0 to 2.0), and other units of soil samples were moderately polluted (NIPI ranged from 2.0 to 3.0). In all, 61.54 and $38.46 \%$ of samples were affected by light and moderate pollution, respectively. Statis-
Table 3. Statistical results of pollution index (PI), Nemerow integrated pollution index (NIPI), potential ecological risk index of a single element $\left(E_{\mathrm{R}}^{i}\right)$ and comprehensive potential ecological risk index (RI).

\begin{tabular}{|c|c|c|c|c|c|c|}
\hline & \multicolumn{5}{|c|}{ PI } & \multirow[t]{2}{*}{ NIPI } \\
\hline & $\mathrm{Cr}$ & $\mathrm{Cu}$ & $\mathrm{Zn}$ & $\mathrm{Cd}$ & $\mathrm{Pb}$ & \\
\hline Maximum & 0.8 & 0.92 & 1.16 & 2.05 & 1 & 1.71 \\
\hline Minimum & 1.13 & 1.13 & 1.42 & 2.84 & 1.22 & 2.24 \\
\hline \multirow[t]{3}{*}{ Mean } & 0.98 & 1.05 & 1.27 & 2.43 & 1.08 & 1.97 \\
\hline & \multicolumn{5}{|c|}{$E_{\mathrm{R}}^{i}$} & RI \\
\hline & $\mathrm{Cr}$ & $\mathrm{Cu}$ & $\mathrm{Zn}$ & $\mathrm{Cd}$ & $\mathrm{Pb}$ & \\
\hline Maximum & 2.26 & 5.64 & 1.42 & 85.12 & 6.12 & 98.61 \\
\hline Minimum & 1.6 & 4.62 & 1.16 & 61.46 & 4.98 & 75.07 \\
\hline Mean & 1.96 & 5.24 & 1.27 & 72.92 & 5.39 & 86.79 \\
\hline
\end{tabular}

tical results of PI and NIPI of heavy metals in soil around the coal gangue dump are listed in Table 3.

\subsection{Concentration distribution of $\mathrm{Cd}$ on the soil profile}

Compared with the background value of soil in the study area, the soil around the coal gangue dump was the most seriously enriched with heavy metal $\mathrm{Cd}$, and the number of sampling points in L2 got the maximum. In addition, L2 is located in the downwind direction. Therefore, the present study chose the L2 sample profile to analyze the vertical change of heavy metal Cd (Fig. 3). 

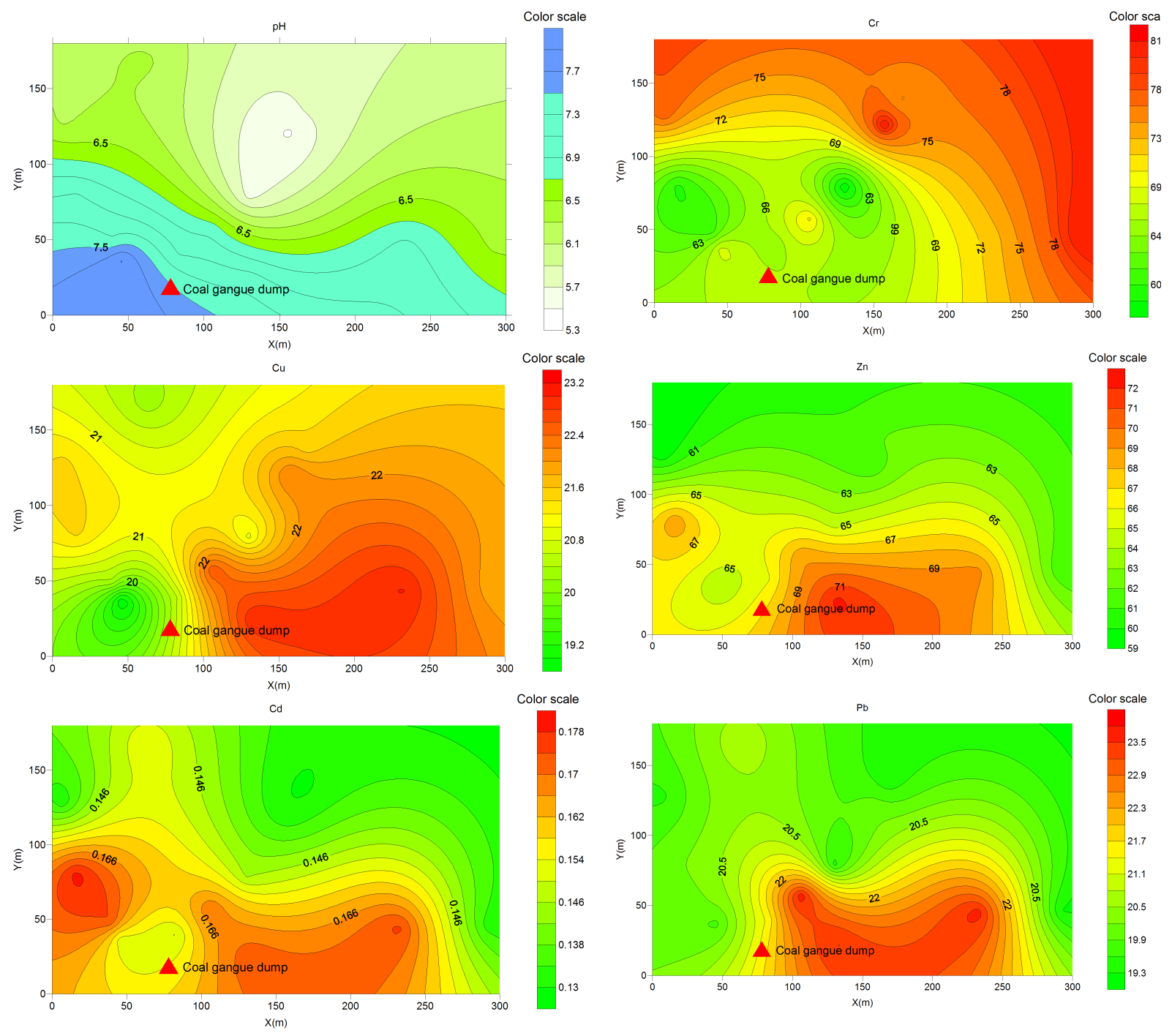

Figure 2. The contour maps of $\mathrm{pH}, \mathrm{Cr}, \mathrm{Cu}, \mathrm{Zn}, \mathrm{Cd}$ and $\mathrm{Pb}$ in the topsoil around the coal gangue dump (the red triangle represents the coal gangue dump).

From Fig. 3, we can see that the concentration of $\mathrm{Cd}$ clearly decreases with increasing distance from the coal gangue dump and with increasing vertical distance from the soil surface.

\subsection{Pearson correlation analysis}

Usually the content of heavy-metal elements originated from the same or similar source tend to have a significant correlation (Hirschfeld, 1935; Rodríguez et al., 2008), so the correlation between the heavy-metal content in soil can be considered as an indicator of whether the source of heavy metal was the same or not. The current study used the Pearson correlation analysis method embedded in SPSS to analyze the correlation among the different heavy metals and the $\mathrm{pH}$ values in soil samples around the coal gangue dump. The correlation

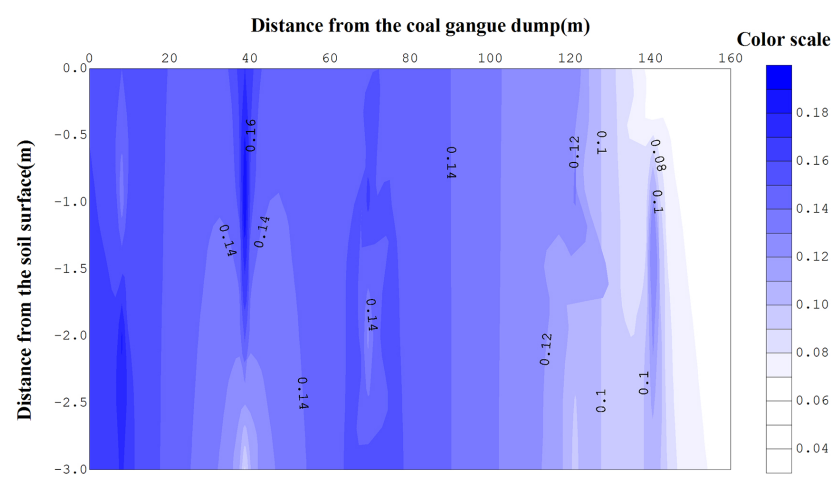

Figure 3. The concentration distribution map of heavy metal $\mathrm{Cd}$ at the $\mathrm{L} 2$ profile. 


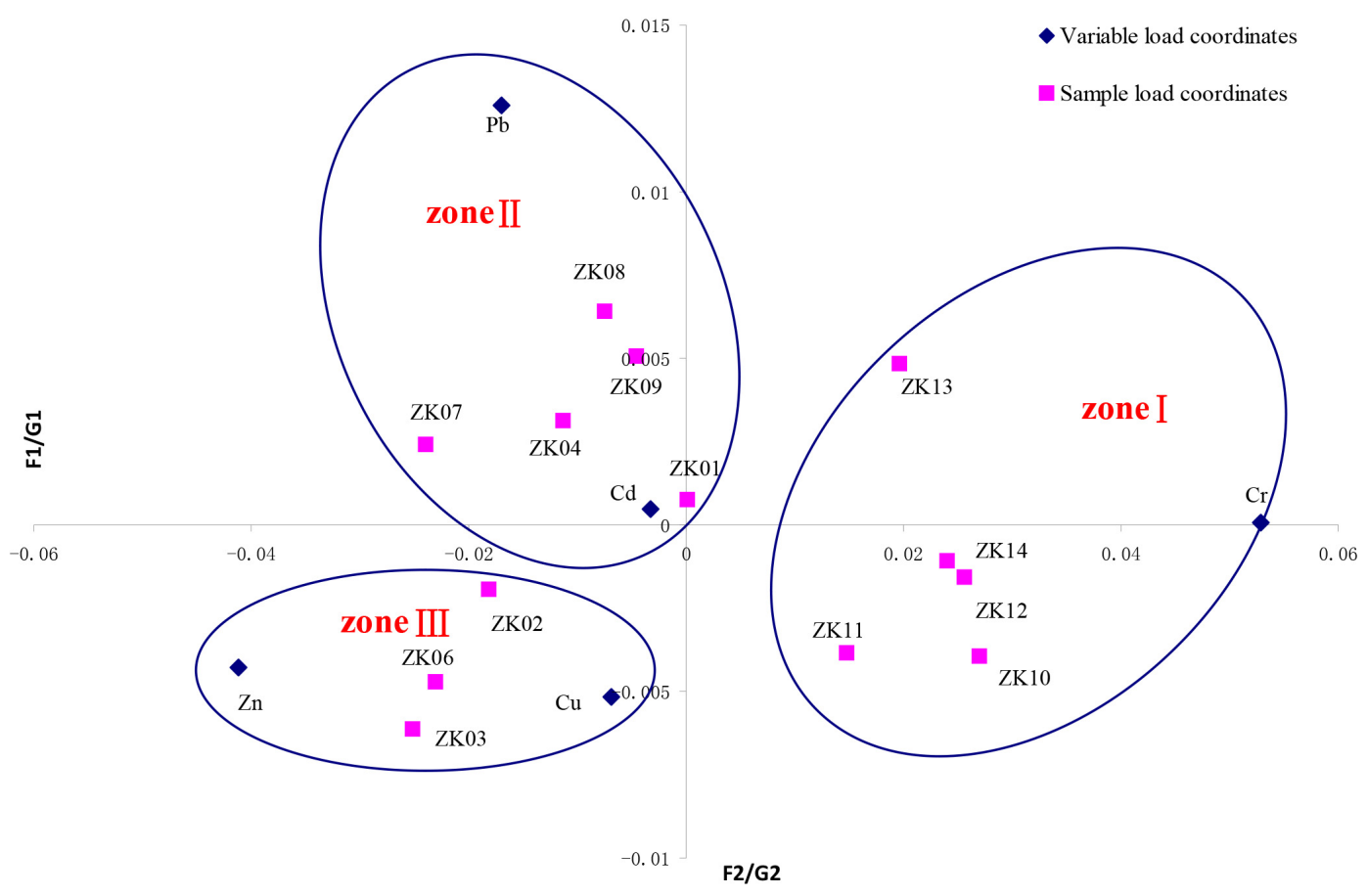

Figure 4. Correspondence map of the relationship between heavy metals and sampling points.

coefficient was defined as follows:

$r=\frac{N \sum x_{i} y_{i}-\sum x_{i} \sum y_{i}}{\sqrt{N \sum x_{i}^{2}-\left(\sum x_{i}\right)^{2}} \sqrt{N \sum y_{i}^{2}-\left(\sum y_{i}\right)^{2}}}$.

Positive correlation between heavy metals suggests that these heavy metals have common sources, mutual dependence and identical behavior during transport. Negative correlations suggest that they do not share the above-mentioned metal traits with each others. The analysis results are listed in Table 4. From Table 4, we can observe that $\mathrm{pH}$ and $\mathrm{Cd}$, $\mathrm{Cu}$ and $\mathrm{Pb}$, and $\mathrm{Cd}$ and $\mathrm{Pb}$ are positively correlated at the 0.01 level, and $\mathrm{Zn}$ is positively correlated with $\mathrm{Cd}$ and $\mathrm{Pb}$ at the 0.05 level, while $\mathrm{Cr}$ is negatively correlated with $\mathrm{Zn}$ and $\mathrm{Cd}$ at the 0.01 level. Moreover, there were significantly positive relationships between $\mathrm{pH}, \mathrm{Cd}, \mathrm{Cu}, \mathrm{Pb}$ and $\mathrm{Zn}$. Based on the above analysis, we can infer that the levels of $\mathrm{Cd}, \mathrm{Cu}$, $\mathrm{Pb}$ and $\mathrm{Zn}$ in topsoil mainly originate from the coal gangue dump, while the concentration of $\mathrm{Cr}$ appears to be controlled by natural sources, and the influence of the coal gangue dump on the $\mathrm{Cr}$ levels was generally low.

\subsection{Correspondence analysis}

Corresponding analysis ( $R-Q$ type factor analysis), proposed by Hirschfeld (1935) and later developed by Benzécri and Bellier (1976), has been applied to indicate the main pollution factor in each soil partition of the study area considering the variable load size and the relationship between variables and the sampling point partition. Correspondence analysis is a robust multivariate statistical method of studying the
Table 4. The results of the Pearson correlation analysis between the different measured indicators.

\begin{tabular}{lllllll}
\hline Correlation & $\mathrm{pH}$ & $\mathrm{Cr}$ & $\mathrm{Cu}$ & $\mathrm{Zn}$ & $\mathrm{Cd}$ & $\mathrm{Pb}$ \\
\hline $\mathrm{pH}$ & 1 & & & & & \\
$\mathrm{Cr}$ & -.395 & 1 & & & & \\
$\mathrm{Cu}$ & -.292 & .258 & 1 & & & \\
$\mathrm{Zn}$ & .542 & $-.591^{*}$ & .418 & 1 & & \\
$\mathrm{Cd}$ & $.670^{*}$ & $-.598^{*}$ & .155 & $.846^{* *}$ & 1 & \\
$\mathrm{~Pb}$ & .368 & -.088 & $.583^{*}$ & $.768^{* *}$ & $.654^{*}$ & 1 \\
\hline
\end{tabular}

* Correlation is significant at the 0.05 level (two-tailed).

** Correlation is significant at the 0.01 level (two-tailed).

relationships between sampling points and variables, underlining $R$ type factor analysis (study of relationships between variables) and $Q$ type factor analysis (study of relationship between samples), and it can reveal variables and samples in the same plane. Using this method, many complicated variables can be compressed into two principal component variables. Subsequently, the relationships between sampling points and variables can be easily analyzed and explained; also, the main variable(s) can be found at the same time (Dillon and Goldstein, 1984; Rodriguez et al., 2008; Uceda et al., 2013; Armand et al., 2013). Figure 4 shows the correspondence map of the relationship between different heavy metals and sample points.

From the distribution trend of sample points, 13 points were divided into three zones. Zone I: ZK10, ZK11, ZK12, ZK13 and ZK14; zone II: ZK01, ZK04, ZK07, ZK08 and 
ZK09; zone III: ZK02, ZK03 and ZK06. The sample points in the three zones were polluted by heavy metals to a different degree.

$\mathrm{Cr}$ was found to have a close relationship with the sample points in zone I. Samples in zone I were located in the outermost of the three sampling lines, relatively far from the coal gangue dump, thus the soil in zone I was less affected by the coal gangue dump. However, the content of heavy metal $\mathrm{Cr}$ in many soil samples in zone I was higher than the background value, long-term crops in this zone may also affect crops.

$\mathrm{Pb}$ and $\mathrm{Cd}$ were closely related to the sample points in zone II. Among them, the sample point ZK8 closely associated with $\mathrm{Pb}$, and the load of $\mathrm{Pb}$ was the largest in the positive direction of the $\mathrm{F} 2$ factor axis, demonstrating that this sample point being to a large extent of $\mathrm{Pb}$ pollution. The relationship between sample points ZK01, ZK04, ZK07 and ZK09 and heavy metal $\mathrm{Cd}$ was close, demonstrating that those sample points being to a large extent of $\mathrm{Cd}$ pollution. In addition, the sampling points (ZK01, ZK04, ZK07 and ZK08) were close to the coal gangue dump; therefore, we can infer that they were mainly severely affected by the heavy metals released through leached process of the coal gangue dump.

$\mathrm{Cu}$ and $\mathrm{Zn}$ were closely related to the sample points in zone III. Zone III was located in the negative direction of the axis of $\mathrm{F} 1$ and $\mathrm{F} 2$, and the distance between sample points in zone III and the coal gangue dump was close proximity, so we can infer that zone III was also mainly affected by coal gangue dump.

\subsection{Single and comprehensive potential risk assessment of heavy metal}

With regard to the Hakanson assessment method, the potential ecological risk index of a single element $\left(E_{\mathrm{R}}^{i}\right)$ and comprehensive potential ecological risk index (RI) were calculated, and the results are shown in Table 3. From Table 3, we can observe that the scopes of the potential ecological risk indices of the five types of heavy metals are $E_{\mathrm{R}}^{i}(\mathrm{Cr}) 1.60 \sim 2.26, E_{\mathrm{R}}^{i}$ $(\mathrm{Cu}) 4.62 \sim 5.64, E_{\mathrm{R}}^{i}(\mathrm{Zn}) 1.16 \sim 1.42, E_{\mathrm{R}}^{i}(\mathrm{Cd}) 61.46 \sim 85.12$ and $E_{\mathrm{R}}^{i}(\mathrm{~Pb}) 4.98 \sim 6.12$. In terms of the mean potential ecological risk indices of the five types of heavy metals, the potential ecological risk arrayed is in the order of $E_{\mathrm{R}}(\mathrm{Cd})>E_{\mathrm{R}}(\mathrm{Pb})>E_{\mathrm{R}}(\mathrm{Cu})>E_{\mathrm{R}}(\mathrm{Cr})>E_{\mathrm{R}}(\mathrm{Zn})$. Cd was the key influence factor to cause the potential ecological risk, and its mean value of $E_{\mathrm{R}}^{i}$ was up to 72.92. All of the sampling points have strong potential ecological risk of $\mathrm{Cd}$, whereas other heavy metals only showed slight potential ecological risk to the environment. In addition, $\mathrm{Cd}$ is the most severe heavy-metal element exceeding the background value in coal gangue. Therefore, $\mathrm{Cd}$ was the key element to be further studied.

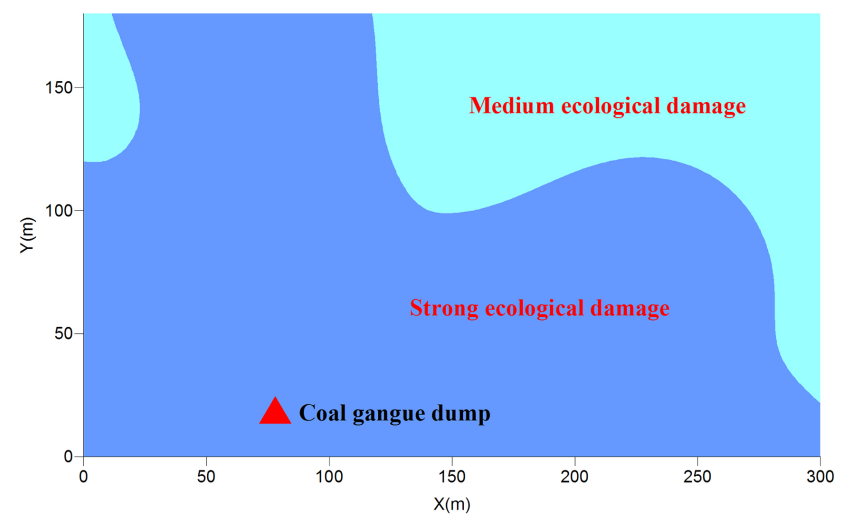

Figure 5. The map of potential ecological damage distribution of soil around the coal gangue dump (the red triangle represents the coal gangue dump).

The scope of RI was $75.07 \sim 98.61$ (Table 3), demonstrating that the soil potential ecological risk levels around the coal gangue dump were level B and C (Fig. 5); the corresponding ecological damage degrees were moderate and strong, respectively. Strong ecological risks have been estimated to exist in the region near the coal gangue dump, while at the region a bit farther from the coal gangue dump, there existed moderate ecological risk. The researches showed that the soil around the coal gangue dump had been polluted to different degrees. Appropriate engineering measures and ecological measures should be taken to control the concentrations of soil heavy metals, and it is also necessary to conduct ecological restoration for the polluted area.

\subsection{Predicted results and discussion}

Cd was the main influence factor to cause the risk based on the above results. Therefore, $\mathrm{Cd}$ was chosen as the key element to predict the pollution trend.

Based on the heavy-metal pollution history of $\mathrm{Cd}$ in topsoil around the coal gangue dump, cumulative acceleration and cumulative rate of heavy metal $\mathrm{Cd}$ were estimated. The fixed number of years exceeding the standard prediction model was also established to predict the pollution trend of topsoil by heavy metal $\mathrm{Cd}$ under the accelerated accumulation mode and the uniform mode. The results were shown in Table 5.

The predicted results indicated that under accelerating accumulation mode, the concentration of $\mathrm{Cd}$ in each sampling point around the coal gangue dump will be higher than primary standard and secondary standard in 10 and 20 years, respectively. Under uniform mode, the concentration of $\mathrm{Cd}$ in each sampling point around the coal gangue dump will be higher than primary standard and secondary standard in 12 and 30 years, respectively. 
Table 5. The fixed number of years exceeding the standard of Cd in soil around the coal gangue dump (year).

\begin{tabular}{|c|c|c|c|c|c|}
\hline \multirow[t]{3}{*}{ Sampling line } & \multirow[t]{3}{*}{ Sample number } & \multicolumn{4}{|c|}{ Fixed number of years exceeding standard } \\
\hline & & \multicolumn{2}{|c|}{ Accelerating accumulation mode } & \multicolumn{2}{|c|}{ Uniform mode } \\
\hline & & $\begin{array}{l}\text { Primary } \\
\text { standard }\end{array}$ & $\begin{array}{l}\text { Secondary } \\
\text { standard }\end{array}$ & $\begin{array}{l}\text { Primary } \\
\text { standard }\end{array}$ & $\begin{array}{c}\text { Secondary } \\
\text { standard }\end{array}$ \\
\hline \multirow{4}{*}{ L1 } & $1-05$ & 6 & 15 & 6 & 19 \\
\hline & $2-07$ & 3 & 11 & 3 & 13 \\
\hline & $3-07$ & 2 & 10 & 2 & 12 \\
\hline & $14-2$ & 10 & 20 & 11 & 28 \\
\hline \multirow{5}{*}{ L2 } & $4-07$ & 6 & 15 & 7 & 20 \\
\hline & $8-08$ & 3 & 11 & 3 & 14 \\
\hline & $6-06$ & 7 & 16 & 8 & 22 \\
\hline & $12-2$ & 10 & 20 & 12 & 29 \\
\hline & $11-1$ & 10 & 20 & 12 & 30 \\
\hline \multirow{3}{*}{ L3 } & $7-05$ & 3 & 11 & 3 & 13 \\
\hline & $9-02$ & 2 & 10 & 3 & 13 \\
\hline & $10-2$ & 9 & 20 & 11 & 28 \\
\hline
\end{tabular}

\section{Conclusions}

This work presents a study on the heavy-metal pollution analysis, potential ecological risk assessment and prediction of soil heavy-metal pollution around the coal gangue dump with the Yangcaogou coal mine as the study area. The present work was performed via investigation, field sampling, laboratory experiment and mathematical analysis. The conclusions can be summarized as follows:

The assessment results of PI indicated that the soil was moderately contaminated by $\mathrm{Cd}$, slightly contaminated by $\mathrm{Zn}$ and $\mathrm{Pb}$, partly slightly contaminated by $\mathrm{Cu}$ and $\mathrm{Cr}$. The pollution degrees descended in the order of $\mathrm{Cd}>\mathrm{Zn}>\mathrm{Pb}>\mathrm{Cu}>\mathrm{Cr}$. In terms of NIPI, 61.54 and $38.46 \%$ of samples were affected by light and moderate pollution, respectively.

The results of Pearson correlation analysis indicated that there were significant positive relationships between $\mathrm{pH}, \mathrm{Cd}$, $\mathrm{Cu}, \mathrm{Pb}$ and $\mathrm{Zn}$, while $\mathrm{Cr}$ was negatively correlated with $\mathrm{Zn}$ and $\mathrm{Cd}$. Based on the Pearson correlation analysis, we can infer that the source of $\mathrm{Cd}, \mathrm{Cu}, \mathrm{Pb}$ and $\mathrm{Zn}$ in topsoil mainly originate from coal gangue dump, while the concentration of $\mathrm{Cr}$ appears to be controlled by natural sources. The results of corresponding analysis revealed that the sample points were divided into three zones. $\mathrm{Cr}, \mathrm{Pb}$ and $\mathrm{Cd}, \mathrm{Cu}$ and $\mathrm{Zn}$ were found to have a close relationship with the sample points in zone I, zone II, zone III, respectively. In addition, the soil in $₫ \tilde{n}$ zone was less affected by the coal gangue dump, while zone II and zone III were mainly affected by the heavy metals released through the leaching process of the coal gangue dump.
The results of potential ecological risk assessment indicated that the potential ecological risk was arranged in the order of $E_{\mathrm{R}}(\mathrm{Cd})>E_{\mathrm{R}}(\mathrm{Pb})>E_{\mathrm{R}}(\mathrm{Cu})>E_{\mathrm{R}}(\mathrm{Cr})>E_{\mathrm{R}}(\mathrm{Zn}) . \mathrm{Cd}$ was the key influence factor to cause the risk, and its mean value of $E_{\mathrm{R}}^{i}$ was up to 72.92 . All of the sampling points demonstrated a strong potential ecological risk of $\mathrm{Cd}$, and other heavy metals in soil around the coal gangue dump only presented a slight potential ecological risk. The range of RI was 75.07-98.61, demonstrating that the soil ecological damage degrees around coal gangue dump were moderate and strong. The potential ecological harms decrease with increasing distance from the coal gangue dump. In conclusion, the research showed that the coal gangue dump polluted the soil around the coal gangue dump. Appropriate engineering measures and ecological measures should be taken to control the concentration of soil heavy metals, and it is important to conduct ecological restoration for pollution area.

The predicted results imply that soil pollution by heavy metal Cd in the study area have a tendency of deterioration within the next few decades. Under an accelerated accumulation mode, the concentration of $\mathrm{Cd}$ in each sampling point around the coal gangue dump will be higher than the primary standard and secondary standard in 10 and 20 years, respectively. Under a uniform mode, the concentration of $\mathrm{Cd}$ in each sampling point around the coal gangue dump will be higher than the primary standard and secondary standard in 12 and 30 years, respectively.

The findings from the present study can provide useful insights for developing a precautionary strategy in the study area, and also will be most important in order to begin ecological restoration of coal mines due to the improper treatment of coal gangue during coal production. 


\section{The Supplement related to this article is available online at doi:10.5194/nhess-14-1599-2014-supplement.}

Acknowledgements. This research was supported by "China Geological Survey Project" (1212011140027 and 12120114027401) and the National Natural Science Foundation of China (41372237). Moreover, the support of the Seed Science Foundation from Ministry of Education of China (450060488107) and Scientific Research Foundation for Returned Scholars of Jilin University (419080500024) are also greatly appreciated.

Edited by: T. Glade

Reviewed by: two anonymous referees

\section{References}

Abdu, N., Agbenin, J. O., and Buerkert, A.: Phytoavailability, human risk assessment and transfer characteristics of cadmium and zinc contamination from urban gardens in Kano, Nigeria, J. Sci. Food Agr., 91, 2722-2730, doi:10.1002/jsfa.4583, 2011.

Armand, S., Lubbeke, A., Hoffmeyer, P., Fritschy, D., Suva, D., and Turcot, K.: Associations between gait and clinical parameters in patients with severe knee osteoarthritis: A multiple correspondence analysis, Clin. Biomech., 28, 299-305, doi:10.1016/j.clinbiomech.2013.01.008, 2013.

Benzécri, J. P. and Bellier, L.: L'analyse des données, Dunod, Paris, 1976.

Dang, Z., Liu, C., and Haigh, M. J.: Mobility of heavy metals associated with the natural weathering of coal mine spoils, Environ. Pollut., 118, 419-426, doi:10.1016/S0269-7491(01)00285$8,2002$.

Dillon, W. R. and Goldstein, M.: Multivariate analysis, Wiley, New York, 1984.

Douay, F., Pelfrêne, A., Planque, J., Fourrier, H., Richard, A., Roussel, H., and Girondelot, B.: Assessment of potential health risk for inhabitants living near a former lead smelter, Part 1: metal concentrations in soils, agricultural crops, and homegrown vegetables, Environ. Monit. Assess., 185, 3665-3680, doi:10.1007/s10661-012-2818-3, 2013.

Dragović, S., Mihailović, N., and Gajić, B.: Heavy metals in soils: distribution, relationship with soil characteristics and radionuclides and multivariate assessment of contamination sources, Chemosphere, 72, 491-495, doi:10.1016/j.chemosphere.2008.02.063, 2008.

Eidukeviciene, M., Volungevicius, J., Marcinkonis, S., Tripolskaja, L., Karcauskiene, D., Fullen, M. A., and Booth, C. A.: Interdisciplinary analysis of soil acidification hazard and its legacy effects in Lithuania, Nat. Hazards Earth Syst. Sci., 10, 1477-1485, doi:10.5194/nhess-10-1477-2010, 2010.

Fan, D. F., Weng, Z. H., Jin, Y., Pan, Y. M., and Zhou, X. M.: Discussions on prediction and precaution methods for soil environment pollution in Lishui County, Jiangsu Province, Jiangsu Geology, 29, 88-93, doi:10.3969/j.issn.1674-3636.2005.02.005, 2005.

Fernandes, H. M.: Heavy metal distribution in sediments and ecological risk assessment: the role of diagenetic processes in reducing metal toxicity in bottom sediments, Environ. Pollut., 97, 317-325, doi:10.1016/S0269-7491(97)00004-3, 1997.
Gong, Q. J., Deng, J., Xiang, Y. C., Wang, Q. F., and Yang, L. Q.: Calculating pollution indices by heavy metals in ecological geochemistry assessment and a case study in parks of Beijing, J. China Univ. Geosci., 19, 230-241, doi:10.1016/S10020705(08)60042-4, 2008.

Hakanson, L.: An Ecological Risk Index for Aquatic Pollution Control: A Sedimentological Approach, Water Res., 14, 975-1001, doi:10.1016/0043-1354(80)90143-8, 1980.

Han, Y. M., Du, P. X., Cao, J. J., and Posmentier, E. S.: Multivariate analysis of heavy metal contamination in urban dusts of Xi'an, Central China, Sci. Total Environ., 355, 176-186, doi:10.1016/j.scitotenv.2005.02.026, 2006.

Hirschfeld, H. O.: A connection between correlation and contingency, Math. Proc. Cambridge, 31, 520-524, doi:10.1017/S0305004100013517, 1935.

Kim, S. C., Yang, J. E., Kim, D. K., Cheong, Y. W., Skousen, J., and Jung, Y. S.: Screening of extraction methods for $\mathrm{Cd}$ and $\mathrm{As}$ bioavailability prediction in rhizospheric soil using multivariate analyses, Environ. Earth Sci., 66, 327-335, doi:10.1007/s12665011-1242-2, 2012.

Krishna, A. K. and Govil, P. K.: Assessment of heavy metal contamination in soils around Manali industrial area, Chennai, Southern India, Environ. Geol., 54, 1465-1472, doi:10.1007/s00254-0070927-z, 2008.

Li, R. Z., Pan, C. R., Xu, J. J., Ding, G. Z., and Zou, Y.: Application of Potential Ecological Risk Assessment Model Based on Monte Carlo Simulation, Res. Environ. Sci., 25, 1336-1343, 2012.

Luan, W. L., Wen, X. Y., Ma, Z. S., Cui, X. T., Song, Z. F., and Du, J.: Geochemical Characteristics of Heavy Metal Elements in Soils of Eastern Hebei Plain, Geoscience, 22, 939-947, doi:10.3969/j.issn.1000-8527.2008.06.007, 2008.

Nabholz, J. V.: Environmental hazard and risk assessment under the United States Toxic Substances Control Act, Sci. Total Environ. 109, 649-665, doi:10.1016/0048-9697(91)90218-4, 1991.

NEPA - National Environmental Protection Agency of China: Environmental quality standard for soils (GB 15618-1995), Standards Press of China, Beijing, 1995.

Querol, X., Izquierdo, M., Monfort, E., Alvarez, E., Font, O., Moreno, T., Alastueya, A., Zhuangd, X., Lud, W., and Wang, Y.: Environmental characterization of burnt coal gangue banks at Yangquan, Shanxi Province, China, Int. J. Coal Geol., 75, 93 104, doi:10.1016/j.coal.2008.04.003, 2008.

Rodríguez, J. A., Nanos, N., Grau, J. M., Gil, L., and LópezArias, M.: Multiscale analysis of heavy metal contents in Spanish agricultural topsoils, Chemosphere, 70, 1085-1096, doi:10.1016/j.chemosphere.2007.07.056, 2008.

Ščančar, J., Milačič, R., Stražar, M., and Burica, O.: Total metal concentrations and partitioning of $\mathrm{Cd}, \mathrm{Cr}, \mathrm{Cu}, \mathrm{Fe}, \mathrm{Ni}$ and $\mathrm{Zn}$ in sewage sludge, Sci. Total Environ., 250, 9-19, doi:10.1016/S0048-9697(99)00478-7, 2000.

Singh, A., Sharma, R. K., Agrawal, M., and Marshall, F. M.: Health risk assessment of heavy metals via dietary intake of foodstuffs from the wastewater irrigated site of a dry tropical area of India, Food Chem. Toxicol., 48, 611-619, doi:10.1016/j.fct.2009.11.041, 2010.

Uceda, J., Carmona, L., Muñoz, A., and Marenco, J. L.: A10.24 Switching Infliximab for New Alternatives: A Correspondence Analysis of Biologics, Reasons to Stop, and Time Periods, 
Ann. Rheum. Dis., 72, A80-A81, doi:10.1136/annrheumdis2013-203224.24, 2013.

Yan, J. Y., Lv, Q. T., and Ge, X. L.: The Research about Soil Heavy Metal Pollution Forecast and Early Warning Support by GIS, Journal of Jilin University (Earth Science Edition), 37, 592-593, 2007.

Yang, J., Chen, J. J., and Wang, X. Y.: Spatial Distribution of Heavy Metals in Soils around the Coal Waste Rock Pile and Their Environmental Pollution Assessment, J. Agro-Environ. Sci., 27, 873878, 2008

Yang, Z. P., Lu, W. X., Long, Y. Q., and Liu, X. R.: Prediction and precaution of heavy metal pollution trend in urban soils of Changchun City, Urban Environ. Urban Ecol., 23, 1-4, 2010.
Yang, Z. P., Lu, W. X., Long, Y. Q., Bao, X. H., and Yang, Q. C.: Assessment of heavy metals contamination in urban topsoil from Changchun City, China, J. Geochem. Explor., 108, 27-38, 2011.

Zhao, H., Xia, B., Fan, C., Zhao, P., and Shen, S.: Human health risk from soil heavy metal contamination under different land uses near Dabaoshan Mine, Southern China, Sci. Total Environ., 417, 45-54, doi:10.1016/j.scitotenv.2011.12.047, 2012.

Zhou, C., Liu, G., Yan, Z., Fang, T., and Wang, R.: Transformation behavior of mineral composition and trace elements during coal gangue combustion, Fuel, 97, 644-650, doi:10.1016/j.fuel.2012.02.027, 2012. 